\title{
Mountain Adventure Tourism: Effect of Personal Value Over Constraint for Its Growth: Case of Kangwon-do
}

\author{
Marie Ndoh Elomba, Lee Seung Koo \\ Kangwon National University, Chuncheon, South Korea
}

\begin{abstract}
The purpose of this research is to examine mountain adventure constraints in relation to personal value attachment of the mountaineering activities. "Mountain adventure tourism" encloses recreational activities which are characterized by high-risk seeking and participation constraints. However, the sector contributes significantly to the relief of isolation and the mental challenge of eradicating boredom. Selecting Kangwon-do in South Korea as a case study, this study attempts to develop a new approach to enhancing growth in mountaineering participation. Since mountaineering is a business enterprise, it can enhance its revenue and attract participation growth through personal value innovation and capitalizing on the personal value of both mountaineers and non-mountaineers. Acknowledging the presence of constraints such as risk in mountaineering participation, the researchers predict that personal value would be a neutralizer to the constraints for "mountain adventure tourism" participation. Additionally, personal value would be a pull factor for pursuing the risk in mountain adventure tourism and constraints minimization will be more effective regarding mountaineering participation, if an individual's personal value for the adventure is high.
\end{abstract}

Keywords: mountain adventure, personal value, constraints

\section{Introduction}

Naturally, humans are inclined to search extraordinary events for the purpose of satisfying and overpowering physical and mental challenges, expressing their valor and strength within their society (Buckley, 2006; 2007; 2012; Mclntyre, 1992). However, in every society, we will find some groups of people who are filled with fear (Carnicelli-Filho, Schwartz, \& Tahara, 2010) due to the aspect of risk(s) involved in finding satisfaction in life and others who are motivated by the risk(s) (Csikszentnihalyi, 1977; Martin \& Priest, 1986). This distinction drives humans to be in either group, i.e., a risk taker or a risk avoider, to participate either actively or passively in risky events or activities. Thus, the fear of risk turns to be a constraint for adventure exploration and yet, it is also seen as a motivator to adventure exploration. Beedie and Hudson (2003) explained that, adventure is broadly accepted to be about uncertain outcome. According to Ewert (1989), "adventure recreation" is synonymous with "risk recreation". Adventure education embodies a variety of self-initiated activities utilizing an interaction with the natural environment that contain elements of real or apparent danger, in which the outcome, while uncertain, can be influenced by the participant and circumstance (Ewert, 1989, p. 6).

Marie Ndoh Elomba, Ph.D., research associate, School of Business Administration, Department of Tourism, Kangwon National University. Email: megfavour2002@yahoo.com.

Lee Seung Koo (Ph.D.), professor of Leisure Studies, School of Business Administration, Department of Tourism, Kangwon National University. 
Adventure recreational activities are those that contain structural components of real or perceived danger and usually involve a natural environment setting in which the outcome is uncertain but influenced by the participant (Ewert \& Hollenhorst, 1997). Examples of activities associated to this term include rock climbing, whitewater kayaking, rafting, sky-diving, mountaineering, scuba diving, and paragliding (Ewert \& Hollenhorst, 1989; Schrader \& Wann, 1999). "Adventurer" is the term used to describe individuals who pursue to participate in risky activities which offer them an expected outdoor excitement (Callander \& Page, 2003). Pursuing the risk involved in adventure, an adventurer looks forward to seeing which places (water, mountains, rocks, deserts, etc.) offer a new experience in relation to the risk. It is argued that the independent pull factor underlining adventure participation is the quest for insight and knowledge rather than risk (Walle, 1997; Weber, 2001). This also depends on whether the adventure is active or passive, because active adventure or "hard" adventure such as mountaineering is inseparable to risk, since risk emerges from uncontrollable externalities (natural risk), while "soft" adventure such as those involved in destination travel has the propensity to have the optimal minimization of the risk involved (Pomfret, 2006). According to Kane and Tucker (2004), the potential definition of "experience" in adventure tourism is constructed freedom to play with reality. Undertaking adventure is individually subjective; thus, it needs self-decision as to what an individual considers as an adventure. Today's increasing search for active and passive activities has expanded the adventure industry especially in developing countries, with an increasing trend in the developed world (Callandar \& Page, 2003). However, previous works suggest that the client's perspective of mountaineering is still under-researched. Would risk be the only constraint or motivation for mountain tourism or adventurous leisure like that of mountaineering?

This research addresses the term "adventure tourism" with an emphasis on mountaineering. It is obvious that apart from risk as a constraint, there are other constraints that restrict participation growth and revenue enhancement. Constraints in leisure studies are extensively studied. Hudson, Hinch, and Walker (2009) presented findings revealing that the constraints for heli-skiing adventure activity were predominantly intrapersonal and structural. But what role would the personal value play over the constraint for adventurous leisure participation?

Only a few authors have sought to answer research questions relating to personal value for participating in risky recreation like mountaineering and other adventure-based activities (Baker \& Crompton, 2000; Russell, 2005). This is a setback, which exerts low demand for advanced mountaineering events or activities in high touristic areas like Kangwon-do. We realized that adventure operators, especially in the mountain-based areas, have not adequately attracted the locals and foreign tourists, because they have paid less attention to the "value" (personal value) aspect that participants and non-participants attached to mountaineering. This further provides the reasons why developing personal value is still not a focus factor for neutralizing the existing participation constraints. For example, it was observed that mountaineers made pioneering climbs in the Rocky and Selkirk ranges. Their desire to reproduce the event brought an additional meaning to the experience, and the photography was not only an extension of what they saw but also what they desired (Brown, 2007). The event of photographing served this desire, and the personal value intrigued continuous participation.

Since adventure comprises the elements of risk and other constraint factors, only the effect of risk and the constraint leisure has so far been addressed by many scholars. Existing literature suggests that the pursuit of these risks is a central attraction of these activities, which implies that the elimination of risk which acts as a constraint for activity engagement is not necessarily an objective since it is virtually impossible (Cater, 2006). According to Morgan, Moore, and Mansell (2005), adventure tourists are categorized into either: fearless 
thrill-seekers, daring thrill-seekers, eco-seekers, or competence-testers. We argue that risk minimization is not the only major strategy to motivate and enact attraction on mountaineering novice. Participation growth will depend strongly on the personal value of the targeted participating group of tourists or individuals.

Considering risk as one major constraint factor to mountain adventure participation will require that management create high value awareness, fortifying perceived value for the events, so as to attract new markets and stimulate existing adventurers or individuals to pursue mountaineering activities. The "marketing management" publication (Kotler \& Keller, 2009) explained that one factor influencing a person's decision is value. Kotler and Keller (2009) reiterated previous publications saying that the only value a company or organization will ever create is the value that comes from the customers. Less than a decade ago, mountaineering became an attractive adventure and appealing to all, including individuals who were not necessarily aspiring mountaineers (Beedie \& Hudson, 2003). This is an added advantage for revenue enhancement; yet, not all of the mountain resource touristic areas, if any, have seen the urgency to exploit this aspect and enhance growth.

Hypothetically, the growth of mountain tourism and mountaineering would not be constrained through high personal value. It is expected that low value will record high constraint levels for each constraint factor against participation, with a correlation between value perception scores and constraints being lower than $50 \%$. This implies that there will be no relationship between mountaineering participation and low personal value for mountain activity. A proper understanding of the effect of personal value will enhance growth in the sector. The study will contribute on how best mountaineering managers or operators can capitalize on the aspect of "value" to enhance revenue and participation growth. In other words, we aim at understanding tourists' personal value for mountaineering activity and to what extend personal value can enhance growth (participation frequency and revenue increase in the sector) despite all the constraints. Personal value as explained with the "value" concept, relating with human behavior for leisure participation, has not been seen as a channel to explore or enhance growth in mountain adventure tourism. This paper would be among the first to establish the ideology that personal value can neutralize constraints for adventure participation.

\section{Literature Review}

\section{Adventure and Tourism}

Previous works (Weed, 2006; Weber, 2001) conceptualized the relatedness between adventure and tourism, answering the question of how adventure recreation relates with tourism in order to establish what we refer to as "adventure tourism". It was established that adventure tourism is viewed essentially as an extension of adventure outdoor recreation (Smith \& Godbey, 1991). An adventure or adventure tourism refers to an independent movement in search of high-risky recreational events by an individual (Buckley, 2012). The independence involved is due to the act of an individual's decision-making to participate in an activity with some degree of risk (high or low risk) which is categorized and evaluated by the individuals involved (i.e., self-evaluation) so as to be considered an adventure regarding those individuals' perspectives (Ewert \& Hollenhorst, 1989). Since adventure encompasses solely outdoor activities, its idea is about exploring a foreign and far-away land, out of one's comfort zone, which introduces the element of tourism (Weed, 2006; Leiper, 1979). Published literature by Weed (2006) and other social scientists explained that adventure recreational activities take place away from the participant's home, requiring the participant's or tourist's movement from the base to the destination environment. Thus, the tourism aspects cannot be ignored. The point of interest to the participant is the activities at the destination area. Tourism has expanded to embrace adventure settings with mountains featuring 
predominantly in such development (Beedie \& Hudson, 2003). Recent development of adventure searching activities gives us a reason to believe that, "adventure" is inseparable from "tourism", because in an adventure exploitation process, there are critical issues like "commodification of the mountain" (Beedie \& Hudson, 2003). Beedie and Hudson (2003) defined commodification as the process by which objects and activities come to be evaluated primarily in terms of their exchange value in the context of trade. One will see that adventure is now packaged as an intangible product to the tourist. The tourist will consequently have higher expectations as the prices for the adventure consumption or experience get higher. However, to reach out for direct revenue growth through increased participation, there is a need to subdue all the major constraints acting against participation. This research suggests that personal value will have strong positive effects over constraints for participation. Previous studies expressed the importance of creating a "protective frame" to ensure enjoyable experiences of mountaineering, along with the key factors that influenced this frame (e.g., guide behavior, equipment, safety management procedures, other tourists, and environmental conditions) (Mackenzie \& Kerr, 2012).

\section{Constraints and Adventure Tourism}

Regardless the type of adventure tourism or the nature of the tourism activity an individual desires to engage in, research in the last decades has justified with the use of both qualitative and quantitative data that tourists are faced with constraints for tourism participation (Hinch \& Jackson, 2000). Several literature sources have explained different measures of constraints. For instance, Jackson and Dunn (1988) and Boothby, Tungatt, and Townsend (1981) dealt with "ceasing participation" as a constraint. Davies and Prentice (1995) referred to "loss of interest" as a constraint; Chick and Robert (1989) provided data that link "anti-leisure" to constraint. Other literature sources dealt with constraints facing non-participants in acquiring leisure or/and tourism to be either internal (i.e., lack of personal skills, abilities, knowledge, and health) or external (lack of time, financial cost, lack of facilities, and transportation problem and background), not leaving out the socioeconomic variation in perception which was also reported to be a barrier to participation (Gilbert \& Hudson, 2000). The scope has also been expanded with the realization that non-participants, like participants, can also be constrained (Jackson, 1983), though not completely but partially in their frequency of participation and interest (Gilbert \& Hudson, 2000; Wright \& Goodale, 1991; Shaw, Bonen, \& McCabe, 1991). It has been shown that non-skiers' perception of skiing can be dominated by negative images of the mountain ski experience which goes beyond cost and fear, to the realms of commitments of time (Williams \& Fidgeon, 2000). According to Williams and Fidgeon (2000), the key to attracting non-skiers is the removal of the major perceived and real barriers that convince a person to reject this form of leisure activity. The success of mountain tourism growth with this strategy is dependent on the different classes of mountaineering participation. The role of personal value assessment to this suggestion is a call of concern, because such barriers can be negotiated through personal value. Statistically, there is a significant difference between groups of adventure tourists reflected in their expectations of the likelihood of injury, constraint, and risk (Morgan et al., 2005).

The concept of "constraints negotiation" was introduced by two groups of investigators who proposed that there might be a negotiation of constraint by an individual to participate in leisure or tourism activity based on the individual's hierarchical series (Crawford \& Godbey, 1987; Jackson, Crawford, \& Godbey, 1993; Gilbert \& Hudson, 2000). In other words, individuals (participants and non-participants) can negotiate their constraint depending on the magnitude of the constraint. Due to the complexity of the issue of constraint, it has recently been classified under three subjects, which include interpersonal (e.g., stress, depression, religiosity, anxiety, 
perceived self-skill, and subject evaluations of the appropriateness of various leisure activities), intrapersonal (the inability to have an associate partner for a chosen leisure or tourism activity), and structural (e.g., economic barriers, availability of time, access, opportunity) constraints (Gilbert \& Hudson, 2000). Data from in-depth interviews on skiing adventure activity by Gilbert and Hudson (2000) suggested that non-skiers were challenged and constrained by the fear of the risk involved, while skiers reported lack of time and discretionary money as their constraint and challenge for participation. Pennington-Gray and Kerstetter (2002) examined constraints for outdoor recreational activity and concluded that individual perception is a constraint to nature-based tourism activity and that structural constraints affecting participation were the most prevalent. It is obvious that there is a big challenge for growth and revenue expansion in the tourism sector, irrespective of the type of tourism or leisure, due to the constraints and challenges that arise from both internalities and externalities. Extensive literature on nature-based tourism (Nyaupane, Morais, \& Graefe, 2004) revealed that there are constraints in adventure participation and these constraints differ with respect to subject category, i.e., either as non-participants, experts, or experienced adventure participants. Thus, several publications have made clear what hinders individuals from leisure, tourism consumption, and adventure tourism which include the excitement in adventure participation (Fleischer \& Pizam, 2002; Gilbert \& Hudson, 2000; Pennington-Gray \& Kerstetter, 2002; McGuire, 1983; 1984; McGuire, Dottavio, \& O'Leary, 1986). Despite the wide scope of constraint studies, little attention is given to other alternatives to minimize the challenge of constraints towards tourists' participation. Previous works suggest that the client perspective regarding mountaineering, as a case study, is still under-researched (Beedie \& Hudson, 2003). The greater concentration on leisure constraint by researchers is of course relevant, but it would be more critically worthwhile now to examine strategic possibilities (e.g., personal value standpoint) of growth in leisure participation, since an alternative view of constraints has recently begun to appear in the literature, summarizing the central proposition that leisure participation is dependent not on the absence of constraints but on negotiation through them (Jackson et al., 1993). Jackson et al. (1993) observed that "constraint" from the leisure perspective does not really stop participation.

\section{Personal Value and Valuing Adventure}

Williams and Soutar (2009) emphasized the critical importance of customer value in the service industry. Rokeach (1973) articulated the behavioral concept with personal value, establishing how personal value shapes and influences human behavior. Recent review of value notes personal values as the most abstract type of social cognition used to store and guide general responses to different classes of stimuli, because they are in a hierarchical order (Madrigal, 1995). It will not be wrong to apply the concept of value from the service marketing perspective to adventure tourism. Tourist consumption and decision-making for adventure participation are backed with the tourist's personal value for the adventure in question.

Values are concepts or beliefs, pertain to desirable end states which transcend specific situations, guide selection or evaluation of behavior and events, and are ordered by relative importance (Doran, 2009). Doran explained that the content of value is the source of motivation and the structure of it is the relationship between the values. From the psychological perspective, personal value is a standpoint of attitude and personal motives - a centrally held enduring belief which guides actions and judgments across specific situations and beyond immediate goals to more ultimate end state of existence (Vinson, Scott, \& Lamont, 1977). Practically, value is measured as a trade-off between benefits and sacrifice. Murphy and Alexander (2000) explained, using the theory of motivation, that motivation influences the choice, frequency, and performance of individuals. 
Literature reported by Madrigal (1995) justifies that a wide range of human behavior is associated with value. These values act as motivation towards an action. Prioritization of personal value would be one fundamental component, determining recreational activity preference. Personal value is a significant predictor of independent travel behavior, because it is more centrally held value (Madrigal, 1995).

Wigfield and Eccles (2000) gave support for this by highlighting that motivation is a determinant from expectancy-value theory. According to expectancy-value theory, behavior is a function of the expectancies that an individual has and the personal value of the goal the individual is pursuing. Such an approach predicts that when more than one behavior is possible, the behavior chosen will be the one with the largest combination of the expected success and value. Expectancy-value theory holds that people are goal-oriented and learners' motivation is determined by how much they value the goal (Wigfield \& Eccles, 2000). This directly implies that a tourist's persistence and performance towards mountaineering adventure would be explained by their value attached to the activity. It is worth saying that growth in adventure tourism, specifically mountaineering, will be more significant if there is more concentration on developing and maintaining an individual's personal value for mountaineering activities. In rock climbing, the idea of getting to the top is not necessarily the primary goal of the adventure but how to get to the top (Jakus, Riddel, \& Shaw, 2003). That is to say, the experience to get the primary objective is what is given more value than the primary objective itself. Risk pursuit, for example, may be a primary value. If so, it will be more of a motivation than constraint. An individual's motivation to perform a certain activity is a function of the expectation of the person's ability to perform the actions and obtain the desired outcome, depending on whether the outcome is associated with personal value (Hsu \& Kang, 2009). Conceptualizing motivation and attitude, it is established that a motivation for an action (e.g., mountaineering) can be influenced by manipulating cues that define an individual's expectation concerning the consequences and incentive value of the action (Hsu \& Kang, 2009).

It should be noted that motivation for recreational participation might intervene and interact with the perception of constraints. Likewise, participation might be determined by the strength of motivation, because individuals who perceived higher level of constraint are less motivated (Carroll \& Alexandris, 1997). Motivation, therefore, must be backed by cognitive component to affect participation constraint. Thus, there is a probability that a high level of personal value can minimize mountain adventure participation constraint. This, therefore, will have a significant effect on adventure growth as regards participation and revenue enhancement. In other words, participation of risky adventure can be fully and exclusively motivated by activating one's personal value for the activity.

\section{Methodology}

Using questionnaires, 324 surveys were collected. Three groups were sampled: regular mountaineers, beginners, and experts. In addition, four mountain activities were chosen. Data were analyzed using SPSS software, guided by leisure constraint theory. Two null hypotheses were stated: (1) There is no relationship between mountaineering participation and low value perception for mountain activity at $95 \%$ confident level; and (2) There is no significant relationship between value for mountaineering and risk (constraints) avoidance at $95 \%$ confident level. It was expected that low value perception will record both low participation frequency and high constraints for participation, with a correlation between value perception scores and constraints being lower than $50 \%$. To enhance the opportunities for mountain adventure growth, there should be a correlation value of $75 \%$ and above. 
Table 1

Demographic Profile of Respondents $(N=324)$

\begin{tabular}{|c|c|c|}
\hline Demographic characteristic & & $\%$ \\
\hline \multirow{2}{*}{ Gender } & Male & 60 \\
\hline & Female & 40 \\
\hline \multirow{2}{*}{ Marital status } & Single & 28 \\
\hline & Married & 72 \\
\hline \multirow{4}{*}{ Age } & $20-25$ & 4 \\
\hline & $26-35$ & 22 \\
\hline & $36-45$ & 23 \\
\hline & $>45$ & 51 \\
\hline \multirow{3}{*}{ Education level } & High school & 32 \\
\hline & B.sc degree & 54 \\
\hline & Graduate and professional & 14 \\
\hline \multirow{5}{*}{ Personal income per month (US\$) } & $<500$ & 16 \\
\hline & $500-1,000$ & 35 \\
\hline & $1,000-2,000$ & 30 \\
\hline & $2,000-3,000$ & 13 \\
\hline & $3,000-4,000$ & 6 \\
\hline \multirow{3}{*}{ Skill level } & Beginner participants & 26 \\
\hline & Intermediary & 59 \\
\hline & Expert/highly experienced & 15 \\
\hline \multirow{4}{*}{ Participation frequency } & Often & 46 \\
\hline & Once in 6 months & 16 \\
\hline & Once in 12 months & 18 \\
\hline & Rarely & 20 \\
\hline \multirow{5}{*}{ Mountaineering activity } & Mountain hiking/climbing & 69 \\
\hline & Mountain biking & 18 \\
\hline & Rock climbing & 7 \\
\hline & Mountain skiing & 5 \\
\hline & All of the above & 1 \\
\hline \multirow{4}{*}{ Usual participation description } & Personally & 12 \\
\hline & With a guide/mountain guard & 7 \\
\hline & Group or companion & 79 \\
\hline & Competition or event & 2 \\
\hline
\end{tabular}

Note. Research sites and sample size records: Seoraksan Mountain $N=182$; MTV Chuncheon Biking Zone $N=98$; Inje Mountain $N=44$.

The study was done during the period of 2010-2011 based on MTV program in Chuncheon city, Kangwon-do province, South Korea. Kangwon province is well known for mountain attraction, and the MTV program that annually features in this province actively triggers mountaineering tourism for both mountaineers and non-mountaineers. Whether or not one is enrolled in the MTV competition, the community in general gets to be part of mountain-related activities during this time. For the purpose of this study, the four main mountaineering activities considered were: ice and rock climbing, mountain hiking/climbing, mountain biking, and mountain skiing. The chosen activities are considered adventurous because of the element of risk and uncertainty involved in participating in these activities, and the mountain sites chosen were specialized areas, popularly known to mountaineering activities: Inje Mountain, Seoraksan Mountain, 
and MTV Mountain biking destinations, Kangwon province. Survey was conducted during winter and spring seasons and on four main mountaineering activities: rock and ice climbing, hiking, biking, and skiing. Subjects for the study include adventure participants at all levels (beginner, regular, and expertise), who were randomly chosen at the selected mountain sites. Table 1 above reports the demographic profile of the sampled population. Following the descriptive demographic profile of the data, less than half of the respondents (46\%) were very much familiar and highly involved in mountaineering following their frequency of participation. Mountain hiking/climbing was the predominant activity which justifies the reason why the majority of the population visited Seoraksan Mountain, a mountain area which is most popular for hiking and climbing.

\section{Scale Development and Measurement}

Intrapersonal, interpersonal, and structural constraints on leisure formed three distinct categories of constraints on leisure (Raymor, Godbey, Crawford, \& Eye, 1993). Empirical research supports that constraint dimension does exist in hierarchy (Crawford, Jackson, \& Godbey, 1991) format depending on the situation. Crawford et al. (1991) explained that such a process of hierarchy affects participation, non-participation, and participation specialization or choices even among leisure participants. Since this study did not focus directly on one of the two general groups of leisure participation (i.e., non-leisure participants or leisure participants only), the items selected for measuring constraint in this study were not strictly confined to a particular dimensional pattern as put forward by the concept of Jackson et al. (1993).

However, the selected items were adapted such that items did not swing away from constraint measures and to best fit both groups of persons. Following the purpose of this study, the researchers intentionally selected specific constraint items that could impair mountain adventure participation growth, for both leisure participants and non-leisure participants. The items were also predominantly constraint items following reviewed research studies (Jackson, 1993; Jackson \& Witt, 1994; Hultsman, 1995; Shores, Scott, \& Floyd, 2007; Williams \& Fidgeon, 2000). Ten constraint items were selected, measured on a 7-point Likert scale (ranging from $1=$ strongly disagree to $7=$ strongly agree) to observe the dependent variable constraint.

Personal value measures were also adapted from previous works of Schwartz (1992), Roccas, Sagiv, Schwartz, and Knafo (2002), and Madrigal (1995). Respondents were asked to rate, based on a 7-point Likert scale (ranging from $1=$ strongly disagree to $7=$ strongly agree), how do they personally value the 13 items selected specifically for this study to measure personal value as reflecting: value for self-enhancement and achievement (e.g., I pay regard to how much I add value to my status when I reach the peak of the mountain), value for openness (e.g., I feel challenged with it, because the mountain activity puts me in a competitive challenge), value for conversation (e.g., I value how much public exposure mountaineering offers me, I value meeting new friends), and value for self-transcendence (e.g., I value the fact that it gives me self-esteem and improves my health). Finally, respondents were asked a direct question to rate their personal value for mountaineering activity considering the risk involved and all the other constraints. This question was also measured on a 7-point scale. A unique question was asked for respondents to give an overall score of how valuable mountaineering is to them on a 10-point Likert scale. This goal, here, was to aviod bias and provide a wide range of valuing mountaineering. 


\section{Data Analysis}

Four steps were applied to analyze the data. Frist, principle component analysis (factor analysis) with a direct oblimin rotation was applied with a fixed number of factor extration equaling to 2 . Retained items were the ones with factor loading $\geq 0.5$, and commu was used to check the construct of measures (see Table 2 below). The reliability of each dimension was tested, which produced a satisfactory Cronbach's alpha $(\geq 0.6)$-an acceptable internal consistency (Hu \& Yu, 2007).

Second, linear regression analysis using the ENTER method was used to observe the possibility of participation growth, considering participation constraint and personal value, with specification to personal value rate score of $\geq 5$ on a 10-point Likert scale. Third, receiver operating characteristic (ROC) curve (Hanley $\&$ McNeil, 1982) was applied to obtain a graphical representation of the relationship between the sensitivity (participation constraint) and specific (personal value) determining cutoff value (Beck \& Shultz, 1986). Forth, risk and personal value were examined regarding participation growth, with the linear regression analysis.

Table 2

Principle Component Analysis

\begin{tabular}{|c|c|c|c|c|}
\hline & $\begin{array}{l}\text { Factor } \\
\text { loading }\end{array}$ & Mean & SD & $\begin{array}{l}\text { Cronbach's } \\
\text { alpha }\end{array}$ \\
\hline \multicolumn{5}{|l|}{ Personal values } \\
\hline $\begin{array}{l}\text { I personally value mountaineering and mountain tourism, because it gives the } \\
\text { opportunity to satisfy my desire to have extra ordinary experience }\end{array}$ & 0.731 & 3.54 & 1.100 & \multirow{12}{*}{0.867} \\
\hline $\begin{array}{l}\text { I personally value the challenge I get from mountain activity. It puts me in a } \\
\text { competitive challenge }\end{array}$ & 0.730 & 3.39 & 1.140 & \\
\hline I personally value the target of reaching the peak of the mountain & 0.718 & 3.57 & 1.156 & \\
\hline Reaching the summit of mountain is what I value most, as an achievement to me & 0.711 & 3.78 & 1.160 & \\
\hline I have a strong personal value and interest for the mountain tourism and mountain activity & 0.700 & 3.61 & 1.068 & \\
\hline The experience is much more important and valuable, whether or not I finish the task & 0.681 & 3.48 & 1.103 & \\
\hline $\begin{array}{l}\text { I personally value the self-esteem and the health improvement for mountaineering. } \\
\text { It is very important to me }\end{array}$ & 0.672 & 3.71 & 1.111 & \\
\hline $\begin{array}{l}\text { I add value to my status when I have successfully climbed to the peak. This is } \\
\text { valuable to me }\end{array}$ & 0.660 & 3.72 & 1.123 & \\
\hline $\begin{array}{l}\text { I value how much of my ability is tested during the activity, i.e., my skill, courage, } \\
\text { daringness }\end{array}$ & 0.650 & 3.14 & 1.149 & \\
\hline Personally, I overall rate mountaineering to be a very valuable involvement ${ }^{*}$ & 0.596 & 6.14 & 2.414 & \\
\hline $\begin{array}{l}\text { I personally like taking risk and I enjoy succeeding in the midst of risk. That is the } \\
\text { reason why I really value mountaineering }\end{array}$ & 0.562 & 3.28 & 1.098 & \\
\hline I personally value how far I can go, not the loss or inability to reach the peak & 0.555 & 3.20 & 1.228 & \\
\hline \multicolumn{5}{|l|}{ Constraints } \\
\hline I could not easily access information for the mountaineering activity & 0.709 & 3.06 & 1.116 & \multirow{10}{*}{0.829} \\
\hline The registration fee is too high & 0.699 & 2.84 & 1.139 & \\
\hline No accompanied friends for the activity & 0.697 & 2.78 & 1.173 & \\
\hline My skill is discouraging & 0.666 & 3.03 & 1.118 & \\
\hline Integrating into mountaineering is difficult, e.g., office location and policy for registration & 0.646 & 3.05 & 1.165 & \\
\hline Bad health & 0.608 & 2.49 & 1.194 & \\
\hline Unfavorable season for group mountaineering & 0.576 & 2.85 & 1.039 & \\
\hline Very expensive equipments are required & 0.543 & 3.36 & 1.206 & \\
\hline I am afraid of the risk & 0.511 & 3.20 & 0.996 & \\
\hline Time is my major problem & 0.502 & 3.22 & 1.090 & \\
\hline
\end{tabular}

Notes. All items: Kaiser-Meyer-Olkin measure of sampling adequacy $=0.845$; Barlett's test of sphericity $=2,942.072 ; \mathrm{df}(276)$ Cronbach's alpha for constraint and personal value combined $=0.813$. Extraction method: Principal component analysis. Rotation method: Oblimin with Kaiser Normalization. The item with ${ }^{*}$ was measured on a 10-point Likert scale. 


\section{Results}

\section{Personal Value and Constraint}

According to this study, mountaineering participation is not significantly constraint $(p=0.46)$ and constraint has $3.1 \%$ predictive power over mountaineering participation. When constraint is controlled by personal value, the observed insignificant level of constraint becomes stronger $\left(p=0.75, R^{2}=0.23\right)$ (see Models 1-2, in Table 3). With the specific selection rule of overall personal value score $\geq 5$ on a 10-point Likert scale, it was observed that constraint has $6.5 \%$ of predictive power over mountaineering participation ( $p=0.14)$ and $9.1 \%$ predictive power over constraint when controlled by personal value $(p=0.45)$ (see Table 3 ). Mountaineering participants with high personal value for mountaineering do not record any significant effect of constraint over their participation $(p=0.75)$. In other words, a positive value perception can attract mountain adventure participation on frequent bases, hence mountaineering growth. It was observed that every constraint item had its own level of prediction over participation frequency, with a significant variation between them.

Table 3

Linear Regression Analysis Using ENTER Method

\begin{tabular}{llllll}
\hline \multirow{2}{*}{ Model } & \multirow{2}{*}{ Predicting dimension } & \multicolumn{3}{c}{ Mountaineering participation } \\
\cline { 3 - 6 } & Constraint & Sig. & $R$ & $R^{2}$ & $F$-value \\
\hline Model 1 & Constraint controlled by personal value & 0.46 & 0.03 & 0.18 & 0.98 \\
\hline Model 2 & 0.75 & 0.05 & 0.23 & 0.77 \\
\hline Model 3 (Selected rule of overall & 3-a constraint & 0.14 & & 0.07 & 1.50 \\
personal value $\geq 5$ was applied) & 3-b constraint controlled by personal value dimension & 0.45 & & 0.09 & 0.98 \\
\hline
\end{tabular}

Notes. $p<0.05$; Model 1: Constraint effect; Model 2: Constraint effect is controlled by all items measuring personal value; Model 3-a: Overall personal value rating score $<5$ on a 10-point Likert scale was applied; Model 3-b: Overall personal value rating score $\geq 5$ on a 10 -point Likert scale was applied.

ROC curve graphically presents the exact point to which personal value affects constraint. In Figure 1, the test variable which states that, "Personally, I overall rate mountaineering to be a very valuable involvement", had at least one tie between the stated variable—constraint. Examining this relationship provided a justification that there is strength of personal value to constraints for mountaineering growth and its effect over constraint was observed. The ROC curve indicates that regardless the intensity of existing constraints, participation frequency is prevented with a high level of personal value. The sensitivity (y-axis) represents the true position rate and 1-specificity ( $\mathrm{x}$-axis) represents the false positive rate, and they both represent the test and stated variable respectively.

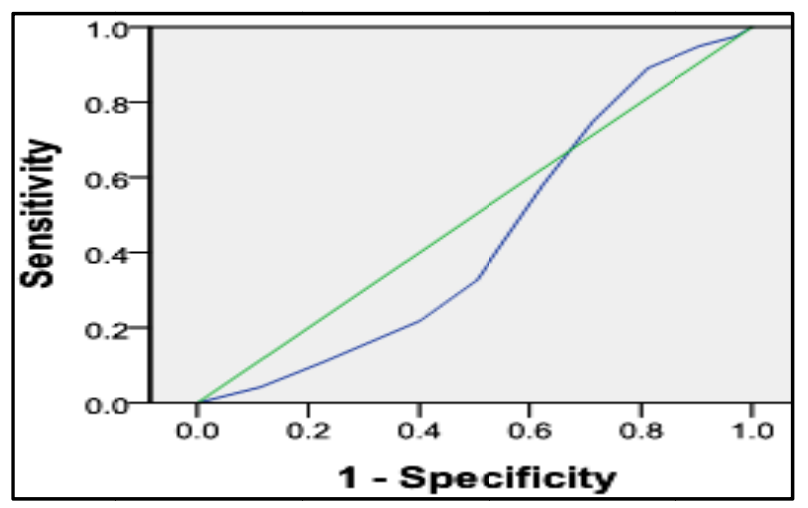

Figure 1. The effect of personal value over participation constraint (ROC curve). 
The diagonal line represents an absolute participatory state for an individual. The curves below the line illustrate participation based on constraint at any given level of personal value rate score. The higher the personal value, i.e., sensitivity for mountaineering, with an existing constraint, i.e., 1-specificity, the closer the curve gets to the diagonal line (absolute state of participation decision). In other words, it reveals a lesser effect of constraint towards participation with an increase in personal value. At an equilibrium point of approximately 0.7 , sensitivity score (value rate) equates the 1-specificity. Above this point of equilibrium between the two variables, individuals are diagnosed with a positive decision for mountaineering participation, whereby the personal value neutralizes existing constraints. Therefore, at a personal value above 0.7 , an individual will have an absolutely positive decision towards mountain adventure tourism participation, regardless the strength of the constraint present. Personal value at this level acts as a neutralizer to constraints' effect on mountain adventure participation.

\section{Risk as a Constraint, Personal Value, and Participation}

The second task was to examine the possibility of participation growth with risk as a constraint factor, under the consideration of personal value. Among the constraint variables, only risk was singled out and observed at this point, because risk has been noted as a factor that can negatively and positively affect the potential growth of mountain adventure (Callander \& Page, 2003). Risk acts as a central attraction for adventure tourism, yet it is also more beneficial if it is reduced (Bentley, Cater, \& Page, 2010). Using linear regression analysis and ENTER method, the result showed that the fear of risk and participation frequency have a positive correlation $(R=0.06)$, but the correlation was insignificant $(p=0.15)$. Coefficient statistics for this relationship showed a lower predictive power of "fear of risk" with participation frequency, and it was also insignificant $\left(R^{2}=0.003, t\right.$-value $\left.=1.028, \beta=0.057, p=0.305\right)$. This result is possible because of the sampled population in question. The goal was to examine this relationship while controlling for personal value. The stated hypothesis (There is a positive relationship between participation frequency in mountaineering and risk-taking, only when personal value is significantly higher) was accepted; personal value $\geq 5$, participation frequency and risk avoidance, $\beta=0.09, t$-value $=1.379$, and $p$-value $=0.169$, while personal value $<5$ reported $\beta=-0.028, t$-value $=-0.256$, and $p$-value $=0.799$. Thus, the greater the personal value for the mountain leisure activity, the more insignificant the risk acts as a constraint on participation frequency. Also, the lower the personal value for the mountaineering, the higher the risk avoidance and the "fear of risk" involved in mountain adventure, which resulted in lower participation frequency, hence a negative effect on mountain adventure growth. In support with previous works (Cater, 2006), it is important to know that whilst effective communication of the thrill within mountaineering proceeds, risk management should be a priority.

\section{Discussion}

The main objective of the study was to examine the importance of personal value over constraint, towards the growth of mountain adventure tourism, considering that there are series of constraint factors for an adventure like mountaineering in which risk is involved. The growth perspective looked at was in the area of participation and frequency of already active mountaineers as well as passive mountaineers. It was observed that personal value can only subdue constraint when it is considerably at a given high rate value (see Figure 1). Until an individual holds a significant level of value perception to adventure (risky adventure like mountaineering), constraints would still have a major role, acting as preventing determinants for participation growth in the sector. 
However, the study reveals that there is no significant constraint effect on mountaineering, which of course is agreeable that constraints are negotiable (Crawford et al., 1991). Constraint can only decrease the level of participation, triggering negotiation resources, to neutralize its negative effect (Hubbard \& Mannell, 2001). This study attests that personal value is one of such major negotiating resources. The result also supports the study of Creyer, Ross, and Ever (2003), who established that participation of high-risk consumption activity is influenced by affective outcome expectancy, and how appealing this activity is will moderate the perceived risk effect on the likelihood of participation. Personal value was measured in this study by using items that did describe and reflect affective attitudes towards the activity, to gain an affective outcome, for example: (1) I value how much of my ability is tested during the activity, i.e., my skill, courage, daringness; and (2) The experience is much more important and valuable, whether or not I finish the task.

Thus, mountaineering operators and mountain tourism destinations have a great challenge of value innovation marketing strategy, for the purpose of mountain adventure growth. Suggestion in this regard, therefore, is to strongly consider that one route to positivity in adventure participation is via developing an internal insight for adventure. Risk management should not only be done in isolation but also with the notion of balance with people's awareness of how well the risk is managed and how management of itself values consumer's personal value for the activity, making sure that safety strategies are fully and practically applied (Bentley et al., 2010).

\section{Conclusion}

Of course, a single study is not sufficient for validating the effect of personal value on enhancing mountain adventure tourism growth (in the area of participation increase and frequency). There is a need to identify and classify personal value into convenient group to best analyze its effect on constraint factors. Although different skill levels of mountaineers were subjected to the study, this paper did not specifically explore its idea of following convenient grouping of different classes of participants and non-mountaineering. Possibly, every society or group of individuals derives their own unique solution towards the balance of social welfare, economic involvement, and demand for leisure or adventure. The difference that personal value makes, to affect constraints, may also be evident with such differentiation. The future of adventure tourism participation, its demand, and sustainability must be critically considered. It is seen that non-adventurers can possibly be attracted when a better understanding of the insight value about such risky leisure consumption is put forth as a major concern of adventure tourism sector, along with assuring training and safety of participants. The survey developed may be modified to test the role of personal value as regards other adventurous activities.

One major limitation of this research which must be addressed in future studies is that this paper did not develop or adopt any unit standard of measurement for personal value, and it did not apply, directly, the already established measure of constraint. There is a call for a proper standard of measurement of personal value of risky leisure consumption.

\section{References}

Baker, D. A., \& Crompton, J. L. (2000). Quality, satisfaction, and behavioral intentions. Annals of Tourism Research, 27(3), 785-804. Beck, J. R., \& Shultz, E. K. (1986). The use of relative operating characteristic (ROC) curves in test performance evaluation. Archives of Pathology and Laboratory Medicine, 110(1), 13-20.

Beedie, P., \& Hudson, S. (2003). Emergence of mountain-based adventure tourism. Annals of Tourism Research, 30(3), 625-643. 
Bentley, T. A., Cater, C., \& Page, S. J. (2010). Adventure and ecotourism safety in Queensland: Operator experiences and practice. Tourism Management, 31(5), 563-571.

Boothby, J., Tungatt, M. F., \& Townsend, A. R. (1981). Ceasing participation in sport activity: Reported reasons and their implications. Journal of Leisure Research, 13(1), 1-14.

Brown, D. A. (2007). The modern romance of mountaineering: Photography, aesthetics, and embodiment. The International Journal of the History of Sport, 24(1), 1-34.

Buckley, R. (2006). Geotourism. Annals of Tourism Research, 33(2), 581-583.

Buckley, R. (2007). Adventure tourism products: Price, duration, size, skill, remoteness. Tourism Management, 28(6), $1428-1433$.

Buckley, R. (2012). Rush as a key motivation in skilled adventure tourism: Resolving the risk recreation paradox. Tourism Management, 33(4), 961-970.

Callander, M., \& Page, S. J. (2003). Managing risk in adventure tourism operations in New Zealand: A review of the legal case history and potential for litigation. Tourism Management, 24(1), 13-23.

Carnicelli-Filho, S., Schwartz, G. M., \& Tahara, A. K. (2010). Fear and adventure tourism in Brazil. Tourism Management, 31(6), 953-956.

Carroll, B., \& Alexandris, K. (1997). Perception of constraints and strength of motivation: Their relationship to recreational sport participation in Greece. Journal of Leisure Research, 29(3), 279-299.

Cater, C. I. (2006). Playing with risk? Participant perceptions of risk and management implications in adventure tourism. Tourism Management, 27(2), 317-325.

Chick, G., \& Robert, J. M. (1989). Leisure and anti-leisure in game play. Leisure Sciences: An Interdisciplinary Journal, 11(2), 73-84.

Crawford, D. W., \& Godbey, G. (1987). Reconceptualizing barriers to family leisure. Leisure Sciences: An Interdisciplinary Journal, 9(2), 119-127.

Crawford, D. W., Jackson, E. L., \& Godbey, G. (1991). A hierarchical model of leisure constraint. Leisure Sciences: An Interdisciplinary Journal, 13(4), 309-320.

Creyer, E., Ross, W., \& Ever, D. (2003). Risk recreation: An exploration of factors influencing the likelihood of participation and the effects of experience. Leisure Studies, 22(3), 239-253.

Csikszentnihalyi, M. (1977). Enjoyment and intrinsic motivation. San Francisco, CA: Jossey-Bass.

Davies, A., \& Prentice, R. (1995). Conceptualizing the latent visitor to heritage attractions. Tourism Management, 16(7), 491-500.

Doran, C. J. (2009). The role of personal values in fair trade consumption. Journal of Business Ethics, 84(4), 549-563.

Ewert, A. W. (1989). Outdoor adventure pursuits: Foundations, models, and theories. Columbus, Ohio: Publishing Horizons.

Ewert, A. W., \& Hollenhorst, S. J. (1997). Adventure recreation and its implications for wilderness. International Journal of Wilderness, 3(2), 21-26.

Ewert, A., \& Hollenhorst, S. (1989). Testing the adventure model: Empirical support for a model of risk recreation participation. Journal of Leisure Research, 21(2), 124-139.

Fleischer, A., \& Pizam, A. (2002). Tourism constraints among Israeli seniors. Annals of Tourism Research, 29(1), 106-123.

Gilbert, D., \& Hudson, S. (2000). Tourism demand constraints: A skiing participation. Annals of Tourism Research, 27(4), 906-925.

Hanley, J. A., \& McNeil, B. J. (1982). The meaning and use of the area under the receiver operating characteristics (ROC) curve. RSNA Radiology, 143(1), 29-36.

Hinch, T. D., \& Jackson, E. L. (2000). Leisure constraints research: Its value as a framework for understanding tourism seasonality. Current Issues in Tourism, 3(2), 87-106.

Hsu, C. H. C., \& Kang, S. K. (2009). Chinese urban mature travelers' motivation and constraints by decision autonomy. Journal of Travel and Tourism Marketing, 26(7), 703-721.

Hu, B., \& Yu, H. (2007). Segmentation by craft selection criteria and shopping involvement. Tourism Management, $28(4), 1079-1092$.

Hubbard, J., \& Mannell, R. C. (2001). Testing competing models of the leisure constraint negotiation process in a corporate employee recreation setting. Leisure Sciences: An Interdisciplinary Journal, 23(3), 145-163.

Hudson, S., Hinch, T., \& Walker, G. (2009). Women's experience and negotiation of leisure constraints in adventure tourism. In Leisure and tourism: International perspectives on cultural practice (pp. 163-179).

Hultsman, W. (1995). Recognizing patterns of leisure constraints: An extension of the exploration of dimensionality. Journal of Leisure Research, 27(3), 228-244.

Jackson, E. L. (1983). Activity-specific barriers to recreation participation. Leisure Sciences: An Interdisciplinary Journal, 6(1), 47-60. 
Jackson, E. L. (1993). Recognizing the patterns of leisure constraints: Results from alternative analyses. Journal of Leisure Research, 25(2), 129-149.

Jackson, E. L., \& Dunn, E. (1988). Integrating ceasing participation with other aspects of leisure behavior. Journal of Leisure Research, 20(1), 31-45.

Jackson, E. L., \& Witt, P. (1994). Change and stability in leisure constraints: A comparison of two surveys conducted four years apart. Journal of Leisure Research, 26(4), 322-336.

Jackson, E. L., Crawford, D. W., \& Godbey, G. (1993). Negotiation of leisure constraint. Leisure Science: An Interdisciplinary Journal, 15(1), 1-11.

Jakus, P., Riddel, M., \& Shaw, D. W. (2003). Are climbers fools? Modeling risky recreation. In N. Hanley, W. D. Shaw, \& R. E. Wright (Eds.), The new economics of outdoor recreation (p. 331). Edward Elgar.

Kane, M. J., \& Tucker, H. (2004). Adventure tourism: The freedom to play with reality. Tourist Studies, 4(3), $217-234$.

Kotler, P., \& Keller, K. L. (2009). Marketing management. Upper Saddle River, NJ: Pearson Prentice Hall.

Leiper, N. (1979). The framework of tourism: Towards a definition of tourism, tourist, and the tourist industry. Annals of Tourism Research, 6(4), 390-407.

Mackenzie, S. H., \& Kerr, J. H. (2012). A (mis)guided adventure tourism experience: An autoethnographic analysis of mountaineering in Bolivia. Journal of Sport and Tourism, 17(2), 125-144.

Madrigal, R. (1995). Personal values, traveler personality type, and leisure travel style. Journal of Leisure Research, 27(2), 125-142.

Martin, P., \& Priest, S. (1986). Understanding the adventure experience. Journal of Adventure Education, 3(1), 18-21.

McGuire, F. A. (1983). Constraint on leisure involvement in the later years. Activities, Adaptation, and Aging, 3(2), 17-24.

McGuire, F. A. (1984). A factor analytic study of leisure constraints in advanced adulthood. Leisure Sciences: An Interdisciplinary Journal, 6(3), 313-326.

McGuire, F., Dottavio, D., \& O'Leary, J. T. (1986). Constraints to participation in outdoor recreation in outdoor recreation across the life span: A nationwide study of limitors and prohibitors. The Gerontologist, 26(5), 538-544.

Mclntyre, N. (1992). Involvement in risk recreation: A comparison of objective and subjective measures of engagement. Journal of Leisure Research, 24(1), 64-71.

Morgan, D., Moore, K., \& Mansell, R. (2005). Adventure tourists on water: linking expectations, affect, achievement, and enjoyment to the sports tourism adventure. Journal of Sport and Tourism, 10(1), 73-88.

Murphy, P. K., \& Alexander, P. A. (2000). A motivated exploration of motivation terminology. Contemporary Educational Psychology, 25(1), 3-53.

Nyaupane, G. P., Morais, D. B., \& Graefe, A. R. (2004). Nature tourism constraints: A cross-activity comparison. Annals of Tourism Research, 31(3), 540-555.

Pennington-Gray, L. A., \& Kerstetter, D. L. (2002). Testing a constraints model within the context of nature-based tourism. Journal of Travel Research, 40(4), 416-423.

Pomfret, G. (2006). Mountaineering adventure tourists: A conceptual framework for research. Tourism Management, 27(1), 113-123.

Raymor, L., Godbey, G., Crawford, D., \& Eye, A. V. (1993). Nature and process of leisure constraints: An empirical test. Leisure Sciences: An Interdisciplinary Journal, 15(2), 99-113.

Roccas, S., Sagiv, L., Schwartz, S. H., \& Knafo, A. (2002). The big five personality factors and personal values. Personality and Social Psychology Bulletin, 28(6), 789-801.

Rokeach, M. (1973). The nature of human values. New York, NY: Free Press.

Russell, J. S. (2005). The value of dangerous sport. Journal of the Philosophy of Sport, 32(1), 1-19.

Schrader, M. P., \& Wann, D. L. (1999). High-risk recreation: The relationship between participant characteristics and degree of involvement. Journal of Sport Behavior, 22(3), 426-442.

Schwartz, S. H. (1992). Universals in the content and structure of values: Theoretical advances and empirical tests in 20 countries. Advances in Experimental Social Psychology, 25, 1-65.

Shaw, S., Bonen, A., \& McCabe, J. F. (1991). Do more constraints mean less leisure? Examining the relationship between constraints and participation. Journal of Leisure Research, 23(4), 286-300.

Shores, K. A., Scott, D., \& Floyd, M. F. (2007). Constraints to outdoor recreation: A multiple hierarchy satisfaction perspective. Leisure Sciences, 29(3), 227-246.

Smith, S. L., \& Godbey, G. C. (1991). Leisure, recreation, and tourism. Annals of Tourism Research, 18(1), 85-100. 
Vinson, D. E., Scott, J. E., \& Lamont, L. M. (1977). The role of personal values in marketing and consumer behavior. Journal of Marketing, 41(2), 44-50.

Walle, A. H. (1997). Pursuing risk or insight: Marketing adventures. Annals of Tourism Research, 24(2), 265-282.

Weber, K. (2001). Outdoor adventure tourism: A review of research approaches. Annals of Tourism Research, 28(2), 360-377.

Weed, M. (2006). Sports tourism research 2000-2004: A systematic review of knowledge. Journal of Sport and Tourism, 11(1), 5-30.

Wigfield, A., \& Eccles, J. S. (2000). Expectancy-value theory of achievement motivation. Contemporary Educational Psychology, 25(1), 68-81.

Williams, P., \& Fidgeon, P. R. (2000). Addressing participation constraint: A case study of potential skiers. Tourism Management, 21(4), 379-393.

Williams, P., \& Soutar, G. N. (2009). Value, satisfaction, and behavioral intensions in an adventure tourism context. Annals of Tourism Research, 36(3), 413-438.

Wright, B., \& Goodale, T. (1991). Beyond non-participation: Validation of interest and frequency of participation categories in constraints research. Journal of Leisure Research, 23(4), 314-331. 